\title{
(2) OPEN ACCESS \\ Cardiac angiosarcoma in the right ventricle treated by surgical resection
}

\author{
Koya Uemura, ${ }^{1}$ Hiroyuki Sano, ${ }^{1}$ Hideyuki Takaoka, ${ }^{1}$ Yutaka Okita ${ }^{2}$
}

${ }^{1}$ Division of Cardiovascular Medicine, Department of Internal Medicine, Aijinkai Takatsuki General Hospital, Takatsuki, Osaka, Japan ${ }^{2}$ Division of Cardiovascular Surgery, Department of Surgery, Aijinkai Takatsuki General Hospital, Takatsuki, Osaka, Japan

\section{Correspondence to}

Dr Hiroyuki Sano; moments_notice_since1980@ yahoo.co.jp

Accepted 19 February 2021

\section{SUMMARY}

Cardiac angiosarcoma is a rare malignant neoplasm, the gold standard treatment is surgical resection. Our patient, an 81-year old Japanese woman, was admitted to hospital after chest pain over a month-long period. Transthoracic echocardiography (TTE) showed a heterogeneous and irregular mass-like lesion measuring approximately $45 \mathrm{~mm}$ and arising from the right ventricular free wall. Transesophageal echocardiography showed the lesion had a mobile portion. Considering the possibility of malignancy and a high risk of embolism and obstruction, we performed surgical resection of the tumour. Histological and immunohistochemical findings led to diagnosis of cardiac angiosarcoma. One year after surgery, TTE and CT showed no evidence of recurrence of angiosarcoma.

\section{BACKGROUND}

Cardiac angiosarcoma is extremely rare. It has rapid progression and therefore a poor prognosis. ${ }^{1}$ Patients with cardiac angiosarcoma often exhibit nonspecific symptoms, such as dyspnoea, cough, fatigue and chest pain after the tumour has grown, and diagnosis and treatment are often delayed. Although advances in imaging technology, such as echocardiography, cardiac MRI (cMRI), and CT, have recently played an important role, diagnosis of cardiac angiosarcoma is still very difficult, but treatment strategy must be decided early after diagnosis. Surgical resection for cardiac angiosarcoma is the current gold standard therapeutic method and is reported to improve the prognosis, but recurrence after treatment is not uncommon. ${ }^{2-4}$ Here, we present an usual case of an elderly woman with a giant primary cardiac angiosarcoma in the right ventricle (RV).

\section{CASE PRESENTATION}

An 81-year-old Japanese woman was admitted to our hospital because of chest pain at rest over a month period. She had undergone surgical treatment for papillary thyroid carcinoma 30 years previously and regularly attended a local hospital for treatment of psychiatric problems and hypothyroidism. On admission, her vital signs were unremarkable (blood pressure $125 / 81 \mathrm{~mm} \mathrm{Hg}$, heart rate 78 beats/min, and oxygen saturation 95\%). Physical examination showed no heart murmur and there was no jugular venous distention or pedal oedema.

\section{INVESTIGATIONS}

An ECG showed a sinus rhythm and an incomplete right bundle branch block. A heterogeneous and irregular mass-like lesion measuring approximately $45 \times 40 \mathrm{~mm}$ was detected by transthoracic echocardiography (TTE) on the RV free wall (figure 1). The tricuspid valve contacted the mass-like lesion during diastole. There was a small amount of pericardial effusion. Transesophageal echocardiography showed a part of the mass-like lesion had mobility (figure 2). Contrast-enhanced CT showed a $51 \mathrm{~mm}$ lobular mass in the RV that involved the pericardium. Heterogeneous contrast enhancement was visible within the mass (figure 3). On cMRI, the mass lesion in the RV had iso-intensity on T1-weighted imaging, and heterogeneous high signal intensity on T2-weighted imaging (figure 4). Positron emission tomography using 18-fluorodeoxyglucose showed increased accumulation consistent with the anterior lower wall of the RV. It was not considered to be metastatic. Coronary angiography showed a normal coronary artery and we could confirm the RV branch from the right coronary artery into the mass.

\section{DIFFERENTIAL DIAGNOSIS}

Cardiac tumours are benign tumours with a frequency of about $75 \%$, but malignant tumours such as angiosarcoma, leiomyosarcoma, or fibrosarcoma, were suspected in this case.

Although malignant lymphoma and metastatic tumours are included as differential diseases,

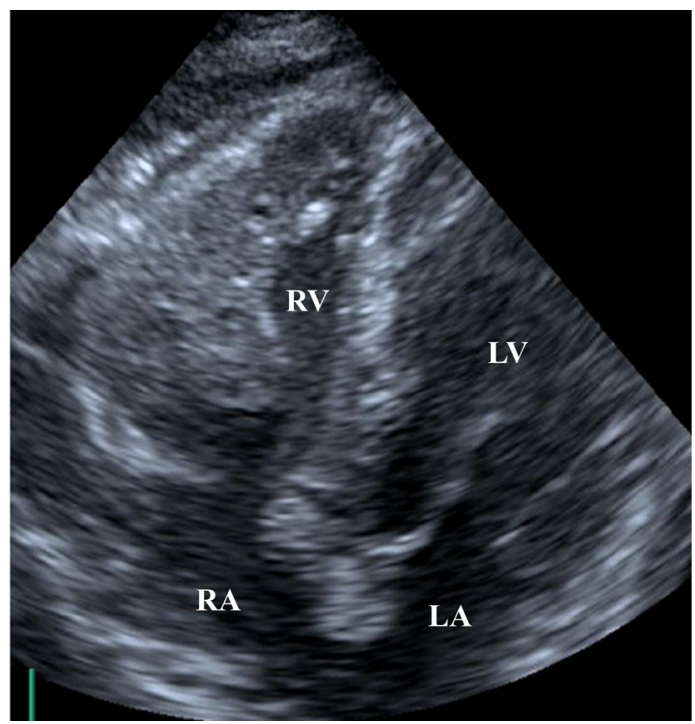

Figure 1 Transthoracic echocardiography showed a heterogeneous and irregular mass-like lesion measuring approximately $45 \times 40 \mathrm{~mm}$ on the right ventricular free wall. Part of it protruded into the epicardium. LA, left atrium; LV, left ventricle; RA, right atrium; RV, right ventricle. 


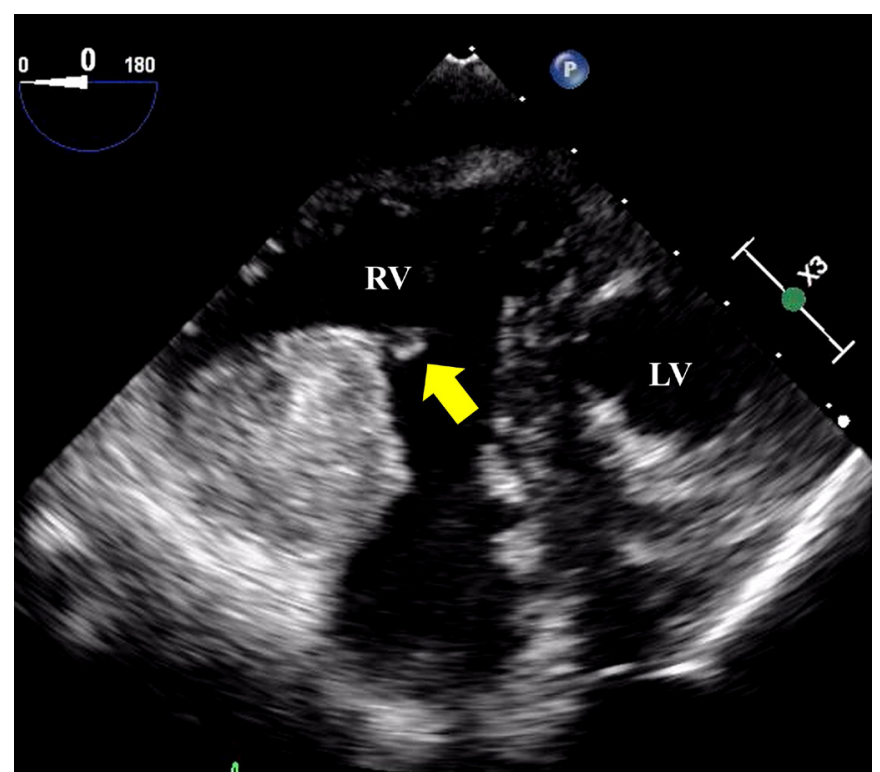

Figure 2 Transgastric short-axis view of transesophageal echocardiography showed part of the mass-like lesion had mobility. LV, left ventricle; RV, right ventricle.

laboratory findings and various imaging modalities were inconsistent with these diagnoses.

\section{TREATMENT}

The mass-like lesion was potentially malignant and had a high risk of embolism and obstruction of the RV from its large size, so we performed surgical resection of the tumour. Cardiopulmonary bypass was established by ascending aortic and innominate venous cannulation in preparation for Glenn surgery in case of haemodynamic failure. After pericardiotomy, the tumour was located from the anterior wall to the apex of the RV (figure 5). The tumour was removed with the adjacent RV wall and then the RV free wall was repaired using an autologous pericardium (figure 6). The chordae tendineae of the tricuspid valve was anchored to the posterior papillary muscle.

Histological findings showed abnormal endothelial cells with large nuclei and good vascularisation. We diagnosed cardiac

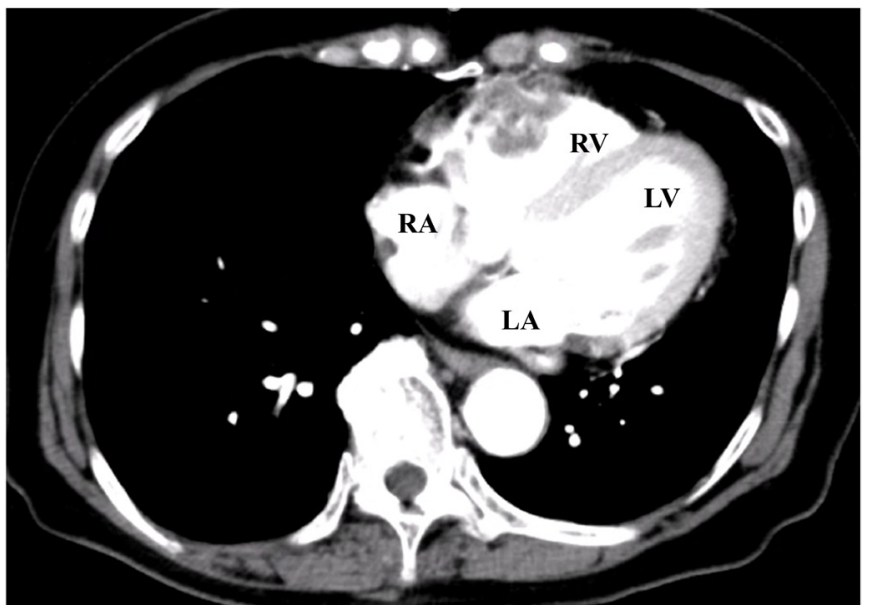

Figure 3 Contrast-enhanced CT showed a $51 \mathrm{~mm}$ lobular mass spreading laterally from the RV, it spread beyond the pericardium, and heterogeneous contrast enhancement could be seen within the mass. $L A$, left atrium; $L V$, left ventricle; $R A$, right atrium; $R V$, right ventricle.

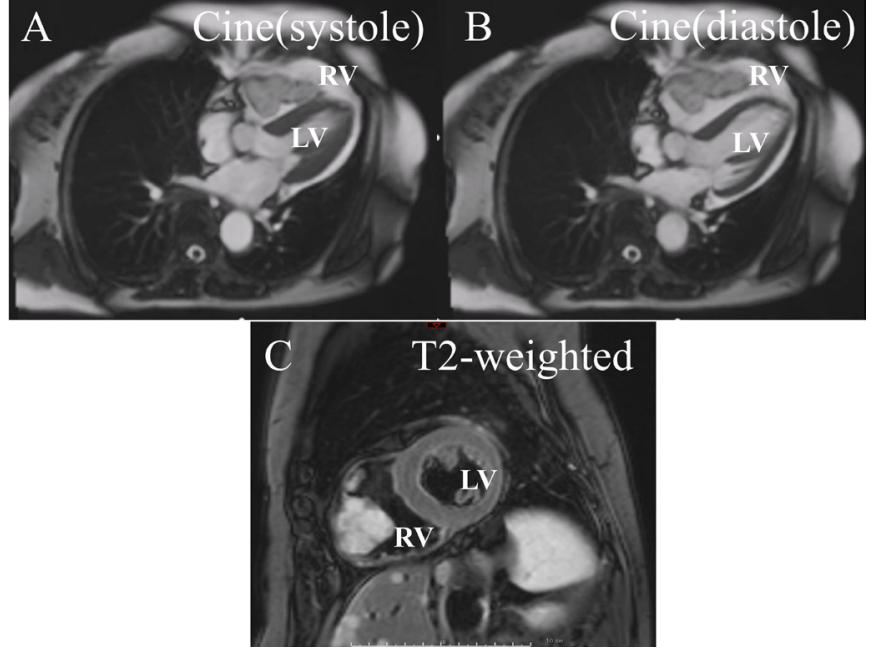

Figure 4 (A, B) Cine images of cardiac MRI (cMRI) for comparison in systolic and diastolic time. The tumour was attached to the anterior wall of the RV. (C) cMRI showed the mass lesion in the RV had heterogeneous high-signal intensity by T2-weighted imaging. LV, left ventricle; RV, right ventricle.

angiosarcoma. No tumour cells were found at the edges of the area where the tumour had been removed. Immunohistochemical findings showed there were CD31-positive vascular endothelial cells, and the tumour cells invaded the epicardium (figure 7).

\section{OUTCOME AND FOLLOW-UP}

One year after surgery, TTE and CT showed no evidence of recurrence of angiosarcoma.

\section{DISCUSSION}

Primary cardiac tumours are very rare with an incidence between $0.001 \%$ and $0.3 \%$ according to autopsy findings. ${ }^{5}$ Approximately, $25 \%$ of cardiac tumours are malignant, of which cardiac angiosarcoma is the most common, accounting for $30 \%{ }^{6}$ Cardiac angiosarcoma occurs more frequently in men than in women at a ratio of 2 or $3: 1,{ }^{7}$ and is more common in younger people, though it can occur at any age. ${ }^{89}$ Although it is found most commonly in the right atrium, it can also be found in the
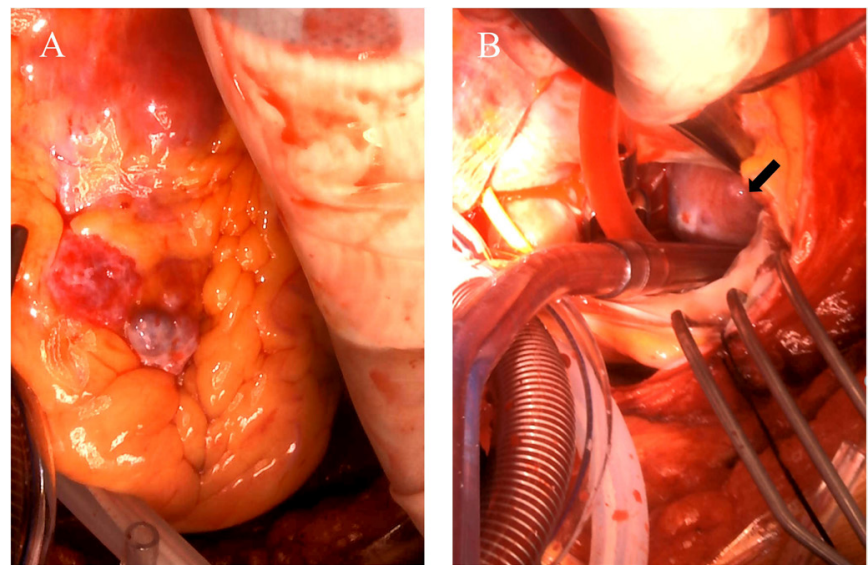

Figure 5 (A) The tumour was located from the anterior wall to the apex of the RV. (B) The tumour in the anterior wall of the RV behind the anterior leaflet of the tricuspid valve after right atriotomy. RV, right ventricle. 


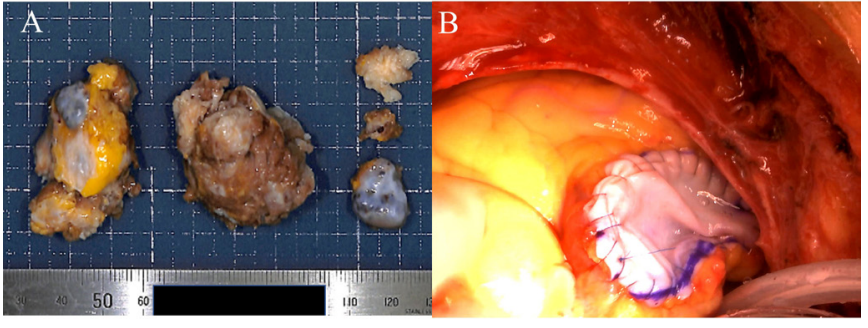

Figure 6 (A) The tumour was slightly white and hard and uneven. (B) The tumour (long arrow) in the right ventricle (RV) was removed and reconstructed with the autologous pericardium.

tricuspid valve, RV, pericardium and right coronary artery. ${ }^{10}$ Patients with cardiac angiosarcoma often exhibit nonspecific and varied symptoms, including dyspnoea, cough, fatigue, chest pain, weight loss, haemoptysis, embolic events and fever. ${ }^{11}{ }^{12}$ Based on the TTE finding that the tumour had reached the epicardium, we thought the cause of the chest pain was due to pericardial irritation.

Early diagnosis of cardiac angiosarcoma is very difficult, but it is important to determine the diagnosis and the course of treatment at an early stage because the mean survival of patients with cardiac angiosarcoma without treatment is reported as $3.8 \pm 2.5$ months. ${ }^{13}$ Recent development of non-invasive imaging technologies, such as echocardiography, CT and cMRI, has contributed to the detection and accurate diagnosis of cardiac tumours. Such imaging can also provide more information about the anatomy of the tumour, the presence of metastases, and the distinction between benign and malignant tumours by evaluation of tissue characteristics. ${ }^{14}$ Microscopically, angiosarcoma is composed of anaplastic cells derived from vascular components, usually with extensive haemorrhage and necrosis inside the tumour. ${ }^{15}$ Contrast-enhanced CT findings of cardiac angiosarcoma therefore show heterogeneous enhancement, ${ }^{16}$ and cardiac MRI findings also show heterogeneous T1-weighted and T2-weighted signal intensity patterns. ${ }^{14}$

Tumour biopsies are rarely undertaken recently, but they could be used to make a specific diagnosis. Meanwhile, Rettmar et al reported that endomyocardial biopsy is inadequate for diagnosis and only $50 \%$ of specimens of cardiac tumours could be diagnosed in their series. ${ }^{17}$ Moreover, biopsies are associated with risks, such as tumour embolisation and bleeding. ${ }^{18}$ In the currently reported case, we did not perform biopsy for histological diagnosis before treatment, and surgical tumour resection was chosen instead. Surgical resection of cardiac angiosarcoma is the gold standard for treatment and has been reported as an important prognostic factor. ${ }^{2-4}$ Anatomical considerations, however, such as the location of the tumour occurrence, infiltration of adjacent tissue, and metastasis, are required to prevent incomplete resection from an inadequate view. Furthermore, even when surgical resection of a tumour is performed with

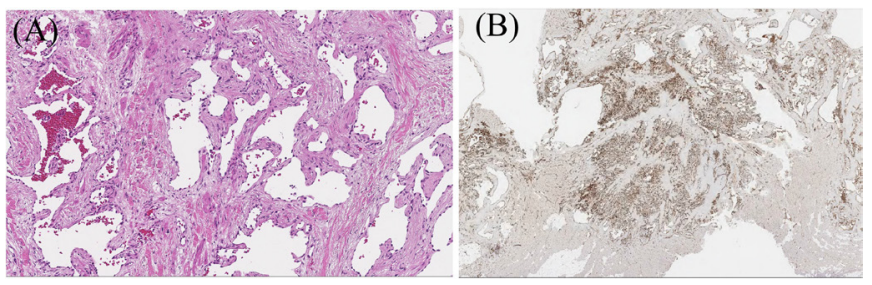

Figure 7 (A) Histological findings showed an increase in abnormal endothelial cells with large nuclei and that they are vascularised. (B) Immunohistochemistry showed many CD31-positive vascular endothelial cells, which were the tumour cells, were growing. negative margins, local recurrence of the tumour is often reported. ${ }^{19}$ Considering additional treatment for recurrence, there are options such as chemotherapy and radiation therapy and their combination with surgical resection has been reported to improve the prognosis of patients with cardiac angiosarcoma. ${ }^{20}$ Meanwhile, the benefits of such adjuvant chemotherapy and radiotherapy remain unclear, and there are still no standard and accurate regimens. Our patient has had no recurrence of the tumour without the need for adjuvant therapy after surgical resection.

\section{Learning points}

- Cardiac tumours should be considered as differential diagnoses for a patient with chest pain.

- Treatment strategies for patients with cardiac tumours may be quickly determined by evaluation of various imaging modalities.

- Early diagnosis using various imaging modalities and surgical resection may result in complete resection without recurrence.

Contributors All authors conceived the conception and design of the case report and discussed planning, analysis and interpretation of data, participated in interpretation of the results and writing of the report. KU, HS and YO have been involved in the patient's care. HS supervised the project. HT and YO performed revising it critically for important intellectual content. All authors approved the final version, and agreed to be accountable for the article and to ensure that all questions regarding the accuracy or integrity of the article are investigated and resolved.

Funding The authors have not declared a specific grant for this research from any funding agency in the public, commercial or not-for-profit sectors.

Competing interests None declared.

Patient consent for publication Not required.

Provenance and peer review Not commissioned; externally peer reviewed.

Open access This is an open access article distributed in accordance with the Creative Commons Attribution Non Commercial (CC BY-NC 4.0) license, which permits others to distribute, remix, adapt, build upon this work non-commercially, and license their derivative works on different terms, provided the original work is properly cited and the use is non-commercial. See: http://creativecommons.org/ licenses/by-nc/4.0/.

\section{REFERENCES}

1 Pigott C, Welker M, Khosla P, et al. Improved outcome with multimodality therapy in primary cardiac angiosarcoma. Nat Clin Pract Oncol 2008;5:112-5.

2 Nakamichi T, Fukuda T, Suzuki T, et al. Primary cardiac angiosarcoma: 53 months' survival after multidisciplinary therapy. Ann Thorac Surg 1997;63:1160-1.

3 Kim MP, Correa AM, Blackmon S, et al. Outcomes after right-side heart sarcoma resection. Ann Thorac Surg 2011;91:770-6.

4 Oh SJ, Yeom SY, Kim K-H. Clinical implication of surgical resection for the rare cardiac tumors involving heart and great vessels. J Korean Med Sci 2013;28:717-24.

5 Patel J, Sheppard MN. Pathological study of primary cardiac and pericardial tumours in a specialist UK centre: surgical and autopsy series. Cardiovasc Pathol 2010;19:343-52.

6 Hoffmeier A, Sindermann JR, Scheld HH, et al. Cardiac tumors--diagnosis and surgical treatment. Dtsch Arztebl Int 2014;111:205-11.

7 Antonuzzo L, Rotella V, Mazzoni F, et al. Primary cardiac angiosarcoma: a fatal disease. Case Rep Med 2009;2009:1-4.

8 Hamidi M, Moody JS, Weigel TL, et al. Primary cardiac sarcoma. Ann Thorac Surg 2010;90:176-81

9 Best AK, Dobson RL, Ahmad AR. Best cases from the AFIP: cardiac angiosarcoma. Radiographics 2003;23 Spec No:S141-5.

10 Hoey ETD, Mankad K, Puppala S, et al. Mri and CT appearances of cardiac tumours in adults. Clin Radiol 2009;64:1214-30.

11 Simpson L, Kumar SK, Okuno SH, et al. Malignant primary cardiac tumors: review of a single institution experience. Cancer 2008;112:2440-6.

12 Kim CH, Dancer JY, Coffey D, et al. Clinicopathologic study of 24 patients with primary cardiac sarcomas: a 10-year single institution experience. Hum Pathol 2008;39:933-8.

13 Butany J, Yu W. Cardiac angiosarcoma: two cases and a review of the literature. Can J Cardiol 2000;16:197-205 
14 Motwani M, Kidambi A, Herzog BA, et al. Mr imaging of cardiac tumors and masses: a review of methods and clinical applications. Radiology 2013;268:26-43.

15 Donsbeck AV, Ranchere D, Coindre JM, et al. Primary cardiac sarcomas: an immunohistochemical and grading study with long-term follow-up of 24 cases. Histopathology 1999;34:295-304.

$16 \mathrm{Yu}$ J-F, Cui H, Ji G-M, et al. Clinical and imaging manifestations of primary cardiac angiosarcoma. BMC Med Imaging 2019;19:16.
17 Rettmar K, Stierle U, Sheikhzadeh A, et al. Primary angiosarcoma of the heart. Report of a case and review of the literature. Jpn Heart J 1993;34:667-83.

18 Cataldi MS. Primary cardiac angiosarcoma Revista dA Socerj 2006;19:87-91.

19 Riles E, Gupta S, Wang DD, et al. Primary cardiac angiosarcoma: a diagnostic challenge in a young man with recurrent pericardial effusions. Exp Clin Cardiol 2012;17:39-42.

20 Sinatra R, Brancaccio G, di Gioia CRT, et al. Integrated approach for cardiac angiosarcoma. Int J Cardiol 2003;88:301-4.

Copyright 2021 BMJ Publishing Group. All rights reserved. For permission to reuse any of this content visit https://www.bmj.com/company/products-services/rights-and-licensing/permissions/

BMJ Case Report Fellows may re-use this article for personal use and teaching without any further permission.

Become a Fellow of BMJ Case Reports today and you can:

- Submit as many cases as you like

- Enjoy fast sympathetic peer review and rapid publication of accepted articles

- Access all the published articles

Re-use any of the published material for personal use and teaching without further permission

\section{Customer Service}

If you have any further queries about your subscription, please contact our customer services team on +44 (0) 2071111105 or via email at support@bmj.com.

Visit casereports.bmj.com for more articles like this and to become a Fellow 